\title{
O MERCADO DA INTIMIDADE: A RELAÇÃO ENTRE VIDA PESSOAL E ESFERA ECONÔMICA
}

\author{
Mariana Zanata THIBES*
}

\begin{abstract}
RESUMO: A exposição da vida pessoal nos meios virtuais tornou-se um fenômeno ubíquo e corriqueiro, que povoa fartamente o cotidiano das pessoas com acesso à internet. Nesse artigo procuramos examinar o fenômeno, propondo uma hipótese explicativa à luz das transformações que envolvem a relação entre sistema econômico e vida pessoal no presente.
\end{abstract}

PALAVRAS-CHAVE: Intimidade. Economia. Privacidade. Internet.

\section{Introdução}

À época em que Walter Benjamin (1989) escreveu, a loja de departamentos era uma das grandes atrações para o flâneur nas ruas de Paris após a Revolução Industrial. Em seu vagar pelas ruas, ele observava o espetáculo urbano, a multidão, as modas, as galerias e as novidades do mundo moderno. As vitrines de vidro refletiam os objetos prontos para capturar o desejo dos passantes, e o flâneur deixava-se inebriar por elas em seu andar contemplativo.

Não por acaso, a figura do flâneur foi lembrada para pensar sobre determinadas experiências relativas à utilização das redes sociais (PRICKETT, 2013). Na flâneurie virtual, somos conduzidos a uma dimensão povoada por imagens ávidas por capturar o desejo dos usuários nas telas dos celulares e computadores. A partir delas, é possível visitar a intimidade dos amigos e das celebridades e contemplar seu estilo de vida. Uma nova legião de influenciadores divulga seu bom-gosto em moda,

\footnotetext{
USP - Universidade de São Paulo. Faculdade de Filosofia Letras e Ciências Humanas. Departamento de Sociologia. São Paulo - SP - Brasil. 05579000 - mthibesster@gmail.com
} 
decoração e gastronomia. Os pertences, cuidadosamente arranjados e fotografados em composições que mostrem o estilo e a autenticidade do proprietário, tornam-se objetos de desejo para os seguidores. O usuário de rede social, por sua vez, parece sentir-se habituado diante dos, quiçá, milhares de olhos virtuais que o podem ver, assim como o flâneur sentia-se em casa em meio à multidão da metrópole. Ele percorre os meandros da rede exibindo os objetos que garantirão a admiração e as curtidas, selecionados cuidadosamente em meio ao repertório dos símbolos de sucesso e coolness. Porém, a analogia da Internet com a flâneurie provavelmente foi mais apropriada nos tempos iniciais da rede, em que ainda havia o encanto de surfar pela web, e a esperança de fazer isso anonimamente. No presente, a própria expressão surfar na web entrou em desuso, assim como tornou-se raro aquilo que faria a cyberflâneurie possível: solidão, anonimato, individualidade, mistério e ambivalência.

Georg Simmel (2002) escreveu sobre a importância do segredo nas sociedades modernas, e sua relação com a individualidade. Ele nos lembra que uma relação só pode ser íntima quando o que se partilha nela é considerado único. Quando o conteúdo de uma relação se torna trivial, ou seja, é replicado com outras pessoas, ela perde seu caráter íntimo e o que a fazia diferente das outras relações. Hoje, boa parte das atividades que antes eram consideradas privadas ou compartilhadas com poucos, são transformadas em dados que expõem nossos interesses, crenças, pensamentos e emoções. Comunicamo-nos por e-mail, mensagens e redes sociais, estabelecemos relações amorosas por meio de aplicativos, procuramos respostas para questões íntimas no Google, transportamonos utilizando aplicativos que monitoram nossa localização, celebramos o nascimento e lamentamos a morte nas redes sociais.

Um dos própositos do Facebook, segundo seu fundador Mark Zuckerberg, é fazer com que tudo se torne social. Isto significa a construção de uma Internet em que assistir filmes, ouvir música, ler livros e até mesmo navegar é feito não apenas de forma aberta, mas partilhada e colaborativa. Com isso, boa parte de nossas atividades seriam compartilhadas não apenas com os aplicativos que promovem os serviços (Facebook, Google, Netflix, Spotify, Waze, etc), mas com a toda a nossa rede social.

Além do compartilhamento ativo das informações pessoais, há o monitoramento invisível e contínuo delas por parte de empresas e governos, que levanta questões relativas ao controle e ao poder das entidades detentoras desses dados. Ademais, o excesso de abertura da vida privada também pode gerar outra sorte de constrangimentos, mais comezinhos, mas que não são de menor importância para a vida social dos indivíduos, como perda de empregos, de reputação, fim de relações e sentimentos negativos. 
Por outro lado, a abertura da vida pessoal promove gratificações importantes, tais como aumento do capital social, manutenção da sociabilidade, acesso a informações relevantes, bem como a possibilidade de retorno monetário àqueles que se expõem. Portanto, é preciso levar esses dois lados do fenômeno em consideração se quisermos compreendê-lo adequadamente. Para isso, retomaremos às origens históricas e sociais do fenômeno e como ele foi debatido pela literatura sociológica mais antiga e recente. Em seguida, apresentaremos o que nos parece ser a explicação mais abrangente e que considera mais profundamente os aspectos sociais, econômicos, políticos e culturais relativos ao significado da exposição da vida privada online.

\section{Nos primórdios, ainda era a televisão}

Embora costumemos pensar que a exposição da vida privada e falta de privacidade sejam fenômenos recentes e diretamente relacionados com a disseminação da Internet, é importante lembrar que a exposição de intimidade em canais de comunicação públicos constitui um fenômeno anterior à disseminação da rede mundial de computadores (embora com muito menos expressividade). $\mathrm{O}$ primeiro registro desse tipo parece ter ocorrido no início da década de 1980, na França, quando uma mulher declarou em um programa de auditório que seu marido sofria de ejaculação precoce e, por essa razão, ela nunca havia experimentado um orgasmo em sua vida de casada. Em meados dos anos 1970, tornaram-se populares os programas televisivos de auditório. Tais programas tinham um formato - utilizado até o presente - de abordar problemas pessoais de convidados junto a plateia. Essa prática despertou a atenção dos pensadores da época, preocupados não apenas com a publicização da vida privada, mas com o fato de que aqueles problemas passaram a ser percebidos como questões de ordem estritamente pessoal e psíquica, deixando de lado as causas sociais e políticas.

Essa interpretação foi a base para o rol de debatores da tese da decadência da esfera pública, que tomou forma no final dos anos de 1970 e começo dos 1980 e foi bastante disseminada nos anos posteriores como tentativa de explicar o que parecia ser o recuo da política para dar lugar a uma esfera privada cada vez mais voraz e ávida por ocupar seus espaços. Essa tese foi também posteriormente mobilizada para explicar o individualismo típico da ordem neoliberal, em que o estímulo à competição mina formas de cooperação e solidariedade essenciais para a ação coletiva (EHRENBERG, 2010).

Para o sociológo francês Alain Ehrenberg (1995), por exemplo, a crise da política estaria relacionada com o fim do Estado de bem-estar social e de suas promessas de emprego e bons salários para todos. A crise econômica e a falência da 
política em dar respostas aos problemas pungentes da sociedade teria feito com que as frustrações e os sofrimentos passassem a ser codificados em linguagem psíquica e buscar resolução na esfera privada. A arena midiática da televisão, do rádio e das revistas ganharam destaque como palco para solução de problemas que passaram a ser vistos como essencialmente privados e individuais. Para Ehrenberg (1995), a TV apenas tornou visível uma crise que já estava disseminada em toda a sociedade e que foi responsável pela recomposição do privado e do público. Assim, além da exibição dos dramas privados, a popularidade dos psy-shows mostra como a TV se torna a via privilegiada para comunicar, de modo privado, as questões pessoais no espaço público. Assim, um dos principais resultados da chamada crise política do pós-80 foi, segundo Ehrenberg (1995), a transferência do campo de batalha para dentro do homem: restaria ao indivíduo lidar com as questões que a política não conseguiria mais responder. $\mathrm{O}$ resultado disso seria um processo de inflação da responsabilidade individual e da subjetividade. A decadência da política torna-se, portanto, a explicação principal para a exposição da vida e dos problemas privados na mídia e outros espaços públicos (mas não políticos).

No mesmo sentido vai a tese de Richard Sennett no livro $O$ Declínio do Homem Público: as tiranias do privado, publicado em 1977, em que o autor procura entender as razões pelas quais, na sociedade contemporânea, as questões públicas não suscitariam mais paixão, que só seria despertada quando o problema fosse tratado como questão pessoal. A superposição do imaginário privado sobre o imaginário público ocorrida ao longo do século XX teria resultado em uma confusão comportamental e ideológica entre os dois âmbitos. Para o autor, o caráter repressivo da sociedade vitoriana, apesar de condenável, era mais compreensível do que o arranjo da sociedade íntima contemporânea, na medida em que a repressão dos sentimentos representava um modo de manter certo grau de invulnerabilidade. Nessa sociedade, a exposição do vigor da personalidade era reservada para arenas públicas com essa função, tais como o teatro. A teatralidade como um todo, no sentido de preservação das convenções e regras de comportamento que marcam distância estaria relacionada a uma vida pública vigorosa. Na sociedade íntima, ao contrário, seriam desprezadas quaisquer formas de teatralidade por seu caráter supostamente inautêntico e não espontâneo que serviria para esconder a verdade do eu. Segundo essa tese, quando a intimidade se sobrepõe aos valores coletivos, a principal forma de reconhecimento é pautada por qualidades pessoais e o sentimento torna-se a principal forma de identificação. Disso resulta a decadência da esfera pública, minada por uma realidade governada por normas narcísicas.

Outro livro que ficou célebre ao tratar da decadência da esfera pública foi A Cultura do Narcisismo de Cristopher Lasch (1979). Embora ele parta das mesmas constatações de Sennett (1977) e Ehrenberg (1995), seu diagnóstico inverte a causa 
do fenômeno ao postular que a decadência da política não teria sido causada por um culto à intimidade, mas pelo colapso da própria intimidade e da personalidade, ocasionado por uma cultura fundada em traços narcisistas. A cultura do narcisismo sinalizaria o recuo dos norte-americanos para as preocupações puramente pessoais: o desenvolvimento psíquico, entrar em contato com os próprios sentimentos, praticar uma alimentação saudável, aprender a relacionar-se, etc. Em outras palavras, o voltar-se para si mesmo mediante o cultivo de tais preocupações egoístas e, por que não, banais, seria o triunfo de um modo de vida narcísico, para o qual soluções políticas não funcionam.

Essas abordagens constituíram um importante diagnóstico de época, mas tornaram-se insuficientes por não refletirem mais as transformações sociais, culturais e econômicas recentes. Os autores foram capazes de identificar importantes transformações nas esferas pública e privada, mas seu diagnóstico limitou-se ao lado puramente negativo das mudanças, vaticinando a decadência de ambas as esferas e a destruição de um determinado estado de coisas imposta pela ascensão imperiosa de uma nova ordem e de um individualismo que minava formas de ação política tradicionais. No entanto, não tiveram condições de observar o que essa nova ordem tinha de positivo, isto é, o que, para além da destruição, ela seria capaz de produzir. Isso foi realizado, cerca de duas décadas depois, pelo sociólogo francês Luc Boltanski e Ève Chiapello, no livro O Novo Espírito do Capitalismo (2009), no qual, além de constatar e atribuir causas e consequências ao que fora extinto, foram competentes para demonstrar como vinha sendo gestada uma nova ordem normativa e valorativa, denominada pelos autores como capitalismo conexionista, e que é, basicamente, o que vivenciamos hoje.

A popularização da Internet e das novas tecnologias da informação e comunicação também adicionaram outras camadas de complexidade à questão, exigindo novas explicações e análises. Se, por um lado, a Internet acentua como nunca a presença da vida privada em meios públicos, criando um nexo nunca antes tão estreito entre vida privada e econômica, por outro, ela também amplia o acesso à informação e as possibilidades de participação política. Assim, se a exposição da vida privada nas redes sociais não pode mais ser pensada a partir da tese da decadência da esfera pública, então qual seria a explicação mais viável para seu entendimento tendo em vista o contexto histórico atual?

\section{O uso das redes sociais e suas motivações}

O Brasil é o país da América Latina com mais usuários de redes sociais, somando um total de 93,2 milhões de pessoas, de acordo com uma pesquisa da 
agência e Marketer do ano de 2016. Outra pesquisa, Digital in 2016 (KEMP, 2016), calculou que o Brasil possuía, no final de $2015,45 \%$ de sua população ativa nas redes sociais. Dentre estas, o Facebook foi a mais utilizada: em 2016, a pesquisa estima que $74 \%$ de todas as pessoas que usam a internet no país tenham uma conta no Facebook. Em seguida, no ranking das redes sociais mais utilizadas pelos brasileiros aparecem o Whatsapp, o Youtube e o Instagram.

As redes sociais ${ }^{1}$ são diversas em sua composição e motivações de uso. Os dados da Pesquisa Brasileira de Mídia 2015, da Secretaria de Comunicação Social da Presidência da República (BRASIL, 2015), mostram que $65 \%$ dos jovens entrevistados, com até 25 anos, acessam a internet todos os dias no país. Entre esses jovens, cerca de $70 \%$ afirmaram que o uso é principalmente destinado à diversão e à busca de notícias.

As redes sociais também se tornaram muito utilizadas por celebridades, empresas e profissionais que buscam visibilidade, ou simplesmente por pessoas que investem na exibição de suas vidas para obter um maior número de seguidores. Grande quantidade de seguidores as classificam no mercado como influenciadoras e atrai empresas interessadas em divulgar produtos, assim como garante notoriedade em determinado campo. Por essa razão, a palavra investimento pode ser utilizada sem que se distancie de sua acepção literal: o retorno obtido com a exibição da vida privada tornou-se, para diversos usuários, financeiro. Esse, entretanto, é um aspecto que escapa à boa parte das abordagens e pesquisas sobre o fenômeno. A maior parte delas centra-se nos aspectos relativos à sociabilidade, tais como obtenção e troca de informação sobre os outros e a manutenção das relações interpessoais (ELLISON; VITAK; STEINFIELD; GRAY; LAMPE, 2011). Outros afirmam que as mídias sociais servem para encontrar pessoas, bem como para receber apoio social (WELLMAN \& GULIA, 1999).

Não se pretende negar a importância de tais motivações para a utilização das mídias sociais pelos indivíduos. A questão da sociabilidade é central para compreender os trânsitos entre o público e o privado nas redes sociais. Todavia, essas abordagens desconsideram aspectos importantes do fenômeno, como a busca por retorno monetário e a crescente profissionalização que envolve o uso da rede. Esses são elementos centrais para compreendermos o balanço entre abertura e proteção das informações pessoais, mesmo entre usuários que não fazem uso profissional da rede. É preciso lembrar que a manutenção da sociabilidade nesses ambientes requer a renúncia de parte da privacidade, de nosso tempo e nossa vida

\footnotetext{
1 Redes sociais são um subdomínio das mídias sociais, definidas como plataformas de comunicação em rede nas quais os participantes 1 ) tem perfis com uma identificação singular cujo conteúdo é fornecido pelo próprio usuário, por outros usuários e/ou pela própria plataforma; 2) podem criar conexões que podem ser visualizadas por outros usuários; e 3) podem consumir, produzir, e/ou interagir com fluxos de conteúdos gerados por suas conexões no site. (Ellison \& boyd, 2013, p.157).
} 
privada para compartilhá-los com os outros. Tais ações acabam sendo naturalizadas quando se perde de vista o contexto histórico em que ocorrem. A Internet é uma tecnologia relativamente recente e não era usual, antes dela, a abertura da vida privada em canais de comunicação públicos. Por isso, é importante assumir como ponto de partida para a discussão que o equilíbrio entre a abertura da vida privada e a privacidade dependerá do contexto social em que se vive: excessos de abertura e de segredo podem desestabilizar essa relação, comprometendo a vida social. Desse modo, é preciso entender de que modo se dá o jogo de compensações que motiva a exposição de si online nesse delicado equilíbrio entre segredo e abertura dos fatos que compõem a vida de um indivíduo.

\section{A exposição de si online: o balanço entre abertura e segredo e suas possíveis explicações}

Uma das mais significativas contribuições da sociologia clássica sobre o tema do equilíbrio entre abertura e segredo está presente na obra de Georg Simmel (2002), para quem certo grau de transparência seria fundamental para as interações sociais e para qualquer tipo de comunicação:

Para o bem da interação e da coesão social, o indivíduo deve saber certas coisas sobre o outro. Este tampouco tem o direito de se opor a esse conhecimento, a partir de um ponto de vista moral, exigindo a discrição do primeiro: ele não pode exigir a posse sem perturbações de seu ser e sua consciência, já que tal discrição pode comprometer os interesses da sociedade. (SIMMEL, 2002, p.323, tradução minha).

A transmissão de informações sobre si, suas ideias e sentimentos é necessária para criar proximidade social e para que relações de confiança se estabeleçam. Nas sociedades modernas, Simmel (2002) identificou diferentes padrões de abertura nas relações: entre conhecidos, desconhecidos, amigos e amantes, naturalmente o grau de exposição irá variar.

Mas o que ocorre quando a exposição de si é cada vez mais intensa e as formas de segredo parecem sofrer um recuo significativo? No presente tornou-se comum o incômodo com excessos de abertura e de vigilância da vida privada, já que boa parte de nossas ações é gravada, armazenada e rastreada por ferramentas digitais. Entretanto, esse incômodo não impediu que a exposição da vida privada tenha se tornado parte do conjunto de ações corriqueiras de todas as gerações, sobretudo, das mais jovens. Compartilhar o que pensamos, comemos, nossas opiniões, viagens, 
passeios, fotos e boa parte daquilo que compõe nossas vidas pessoais deixou de ser algo que realizamos apenas com pessoas íntimas e conhecidas. Cada usuário de rede social tem, hoje, em média, 155 usuários em sua rede com quem compartilha informações. Embora certamente haja aqueles que preferem agir com cautela no que diz respeito a compartilhar informações privadas, o arsenal das redes sociais é fartamente composto de dados pessoais e privados de seus usuários.

O que torna as redes vivas é o fluxo de informações entre nós de rede individuais. Sem informação que flui entre indivíduos, a rede se tornaria um ambiente estático e socialmente pobre (PAPACHARISSI, 2009). Stutzman (2006) referiu-se a este atributo como a socialidade inerente das comunidades de redes sociais e explicou que ela é responsável pelo alto nível de divulgação de informações pessoais on-line. Para se manterem sociais, mas também gerenciar a informação privada e pública com habilidade, os indivíduos devem tomar decisões críticas sobre como compartilhar informações em ambientes em rede que instigam essa prática.

Pesquisa conduzida por Acquisti, Stutzman e Gross (2012), entre os anos de 2005 e 2011, com usuários do Facebook, para entender as mudanças de comportamento em relação à privacidade nesse período, descobriu que, nos primórdios da rede havia uma preocupação maior com a privacidade, e os usuários procuravam limitar progressivamente os dados publicamente compartilhados com estranhos (usuários de Facebook não pertencentes à mesma rede). No fim do período pesquisado, a tendência inverteu-se, e os usuários passaram a compartilhar publicamente cada vez mais informações privadas, isto é, tornando-as visíveis para qualquer usuário daquela rede social. Com isso, as revelações para os ouvintes silenciosos também aumentaram: o próprio Facebook, outros aplicativos e os anunciantes passaram a ter amplo acesso a informações voluntariamente reveladas pelos facebookers. Trepte e Heinecke (2011) também mostraram que, quanto maior a frequência de uso das redes sociais, maior a tendência à abertura de si online, já que essa ação seria reforçada por meio do capital social que circula nesses ambientes.

Porém, se por um lado a exibição da vida privada nas redes sociais pode aumentar o capital social de quem se exibe, por outro, ela também pode causar certos tipos de incômodo. Um estudo feito pelo Pew Research Center (MADDEN, MARYET et al, 2013) mostrou que os jovens se sentem desgastados com o excesso de informações compartilhadas, mas eles continuam a utilizar as redes sociais porque elas são cruciais para sua vida social. De modo similar, a pesquisadora Ilana Gershon (2011) descobriu, a partir de entrevistas com estudantes da Universidade de Indiana, que seus entrevistados se incomodavam com o excesso de informações pessoais presentes no Facebook, que julgavam ser uma ameaça a seus relacionamentos, por transformá-los em pessoas ansiosas, ciumentas, controladoras e invejosas, o que 
levou alguns deles a desativar a conta na rede social. Porém, apesar de parecer fácil, a saída da rede social criou outros problemas para os desistentes, obrigandoos a abrir mão de conexões e informações importantes para a manutenção de sua sociabilidade, o que os fez, depois de pouco tempo, reativar a conta.

Para Gershon (2011), os sentimentos negativos relatados pelos estudantes de sua pesquisa eram sintomas de dois problemas principais. O primeiro seria a falta de contexto que circunda as informações publicadas na rede social. Seus entrevistados afirmaram ter dificuldade para interpretar as relações estabelecidas por seus companheiros por meio de uma comunicação sem contexto, permeada pelo excesso e pela incompletude informacional simultaneamente. Mas se a exposição gera problemas e sentimentos negativos, por que continua a ocorrer? Para que o usuário das redes sociais continue a se expor, ainda que como resultado possa ter problemas pessoais e sentimentos negativos, é preciso que haja também algum recurso bastante poderoso que motive a adesão a esse tipo de prática. Já se tornou parte do discurso corrente a ideia de que as pessoas abrem mão de sua privacidade por desconhecimento das consequências que a exposição geraria. No entanto, embora isso possa ocorrer, não está entre as razões fundamentais. Uma pesquisa conduzida por Alessandro Acquisti e Ralph Gross (2006) com usuários universitários do Facebook mostrou que os mais preocupados com a privacidade online tendiam a se expor mais do que os que revelavam menor preocupação com o assunto. Os autores detectaram pouca ou nenhuma relação entre as atitudes de proteção à privacidade relatadas pelos participantes e suas propensões a publicar informação pessoal online. Mesmo entre os estudantes mais preocupados com a sua privacidade, cerca de $40 \%$ revelavam os horários de suas aulas na rede, $22 \%$, o endereço de suas casas e 16\% publicavam ambas as informações. Isso mostra que, mesmo conscientes acerca dos perigos relativos à exposição de si na Internet, os jovens não deixam de fazê-lo.

Essa constatação vincula-se ao segundo problema identificado por Gershon (2011) qual seja, a transposição de princípios neoliberais aos selves dos jovens. $\mathrm{O}$ Facebook os encoraja a se apresentarem como um "conjunto flexível de habilidades, traços úteis e gostos (de consumo) que precisam ser constantemente aprimorados", bem como a se engajarem em relações do tipo "neoliberal", isto é, conexões fracas e funcionais a serem ampliadas constantemente (GERSHON, 2011, p.867). Isto resultaria na pressão relatada para gerenciar o perfil como um conjunto flexível de habilidades e gostos que precisam de cuidado e melhoramento contínuos. Em outras palavras, o eu do perfil seria administrado como se fosse um negócio, de modo a estar pronto a se aliar e competir com outros selves estruturados da mesma forma. Essas alianças seriam sentidas como arriscadas e necessárias e também obedeceriam a um critério quantitativo. Desse ponto de vista, quanto mais qualidades o eu 
apresentar, melhor; e quanto mais conexões tiver, também melhor, pois significa que há mais capital social em jogo.

A própria Internet, nesse sentido, não escapa à lógica neoliberal. Citando Jodi Dean (2009), Gershon (2011) lembra que a lógica a mover a rede é quantitativa: a do maior número de acessos a uma página e do maior número de amigos numa rede social. Preocupações com a duração e a profundidade das relações tornaram-se problemas de baby-boomers presos ao passado. Uma de suas entrevistadas afirmou: "Você tem de apresentar a foto perfeita no perfil, que deve ser atualizada pelo menos uma vez em poucos meses. Se você não o fizer, você é um loser" (GERSHON, 2011, p. 874). Outra entrevistada deixava claro como se sentia competitiva em relação a uma garota de quem suspeitava estar paquerando seu namorado:

Eu tenho mais amigos do que ela no Facebook, mais amigos que ativamente escrevem na minha página e mais fotos do que ela, então sou uma cyber-persona mais popular, embora, na verdade, eu seja uma eremita. Moro sozinha e tenho um cachorro. Não saio, de fato, com essas pessoas. Mas parece que saio (GERSHON, 2011, p.874).

Assim, há dois aspectos em questão: por um lado, os excessos de abertura da vida privada podem ter consequências danosas, mas, por outro, a exposição de si também proporciona gratificações importantes, de ordem simbólica e material. Acreditamos que não é possível compreender devidamente o problema sem levar em consideração esses dois lados.

Gershon (2011) notou um aspecto fundamental em sua etnografia dos estudantes usuários de redes sociais: na competição por bens sociais importantes (o amor do namorado, a popularidade, entre outros) é preciso agir conforme determinados critérios (ter a foto perfeita, ter maior número de amigos. A autora não apenas conclui que há uma relação entre abertura da vida pessoal e maiores gratificações por meio das redes sociais, mas que essa abertura deve obedecer a determinados padrões, estar de acordo com uma determinada ordem normativa, que ela denominou como neoliberal. Resta entender como essa ordem se impôs e quais são as formas de ação e as crenças que ela incita, e como elas se refletem no fenômeno aqui examinado.

\section{A exposição de si online e os valores do capitalismo conexionista}

No começo do texto indagamo-nos acerca das motivações em jogo na exibição de informações pessoais online. Como mostrou a entrevistada de Gershon 
(2011), a competição por bens sociais de importância fundamental entra em ação na hora de criar e gerenciar o eu virtual, desde os simbólicos - como a reputação (ou a preservação da face/fachada, usando o conceito de Goffman [2005]), o reconhecimento dos pares, o capital social e o status -, aos bens concretos como parceiros amorosos, empregos, amigos e renda. No caso da entrevistada de Gershon (2011), havia a competição pelo amor do namorado. Por meio do que ela chamou de sua popularidade, ou de sua correta apresentação na rede social, ela sentia que ganhava a competição com a outra garota, ao ostentar uma imagem ideal, pouco importando se, na verdade, não conseguisse sustentá-la na vida off-line. Resta entender quais são os critérios que informam essa competição e embasam a construção dessa imagem ideal, garantindo o acesso às gratificações simbólicas e materiais.

O que se pretende argumentar aqui é que a constelação valorativa própria ao capitalismo conexionista cria um cenário no qual se expor, publicizar os feitos, as realizações e as qualidades do eu, nas redes sociais e na Internet em geral, se torna extremamente importante para obter acesso a bens sociais fundamentais: um trabalho, um par amoroso, amigos, conexões, capital social, popularidade, reconhecimento e dinheiro.

$\mathrm{Na}$ etapa histórica denominada por Boltanski e Chiapello (2009) como terceiro espírito do capitalismo, ou capitalismo conexionista, a vida pessoal, tendo estado distante do mundo do trabalho e da esfera pública como um todo no começo do século XX, é novamente trazida à baila e incorporada ao sistema produtivo, adquirindo papel central na constelação valorativa do capitalismo avançado. Uma série de mudanças dá início ao novo espírito identificado por Boltanski e Chiapello (2009). Seu grande marco simbólico são as revoltas ocorridas em maiojunho de 1968 na França, que desferiram um golpe mortal no segundo espírito do capitalismo, desacreditando suas formas de justificação como arcaicas, autoritárias e irreais. A confluência entre as críticas estética e social ${ }^{2}$ que aparece nessa crise promove uma contestação geral dos pilares que organizam o antigo espírito: o descrédito na possibilidade de construir uma carreira estável, o descontentamento com a impessoalidade, a frieza e a rígida hierarquia das grandes organizações racionalizadas, a inautenticidade, a falta de autonomia e flexibilidade, assim como diferentes formas de opressão do mundo moderno. Na esfera do trabalho e da produção predomina a crítica ao poder hierarquizado, ao autoritarismo, aos horários

\footnotetext{
2 A crítica estética, simbolizada pelas revoltas de 1968, corresponde a uma demanda por liberdade em relação às formas hierárquicas e burocratizadas, e ao clamor por autenticidade como reação à massificação característica das grandes sociedades industrializadas. A crítica social, por sua vez, articulada pelos movimentos trabalhadores, centrou-se nas demandas sociais, principalmente na concessão de melhores salários e condições de trabalho.
} 
impostos, às tarefas prescritas, à separação tayloriana entre concepção e execução (BOLTANSKI; CHIAPELLO, 2009).

Um dos pontos-chaves do livro de Boltanski e Chiapello (2009) é mostrar como essas críticas foram desarmadas pelo capitalismo conexionista (que muitos preferem chamar de neoliberal), a partir da incorporação de seus diversos pilares ao próprio sistema. Assim, se nos anos 60 temia-se qualquer presença de laços familiares entre os empregadores que pudessem comprometer a racionalidade ou objetividade da administração, a literatura gerencial da década de 1990 passa a conferir um lugar completamente diferente para a vida pessoal. A crítica à inautenticidade e às formas rígidas hierárquicas é respondida com uma mudança dos princípios gerenciais, que trazem para o centro da cena as qualidades e méritos pessoais dos funcionários. Estes, também passam a ser avaliados de modo individualizado, a partir de seu desempenho e produtividade, que são considerados como parte indissociável de suas qualidades pessoais. Dessa forma, o envolvimento dos indivíduos nos projetos do mundo conexionista depende diretamente de suas qualidades pessoais - o modo como se relaciona com os pares, autonomia, empreendedorismo, iniciativa, flexibilidade (para trabalhar em múltiplos projetos), comunicabilidade, equilíbrio psicológico (capacidade de suportar pressão), sociabilidade (para fazer contatos), entre tantas outras características que devem ser cultivadas e reveladas oportunamente.

Essas qualidades serão utilizadas como medida de valor para julgar competências e méritos; elas criarão um repertório, uma linguagem, que transpassará o âmbito das corporações e irá se instalar em outras esferas. Como explicam Boltanski e Chiapello (2009), diferente do segundo espírito do capitalismo, em que vigorava a nítida separação das aptidões profissionais e pessoais dos trabalhadores, no terceiro, essas duas dimensões da vida foram fundidas. As qualidades mais pessoais dos indivíduos, isto é, aquelas relacionadas ao seu caráter, passaram a ser vigorosamente valorizadas. Mediante técnicas da psicologia do trabalho, passa a ser feita a seleção de candidatos que possuam essas características e que são, presumidamente, mais adaptados (ou adaptáveis) às novas exigências do mundo empresarial.

No entanto, a posse dessas características não é apenas um dado genético. É preciso cultivá-las para desenvolver os recursos internos individuais e assim garantir uma boa imagem de si. Esta, por sua vez, resulta em boas redes, boas conexões e amplo reconhecimento. Entretanto, apenas o cultivo das qualidades individuais não é suficiente. Nesse ponto, é possível estabelecer mais claramente a relação entre o capitalismo conexionista e as Novas Tecnologias de Informação e Comunicação (NTIC). Embora os autores não realizem essa conexão de modo explícito no livro, ela certamente pode ser aventada na medida em que as afinidades são claras e já 
percebidas por outros autores ${ }^{3}$. As redes sociais, por exemplo, têm papel evidente como vitrine para a apresentação do eu e para a exibição das características certas, dos sinais de sucesso, que garantirão a ampliação das conexões e o reconhecimento dos pares. Como afirmam Boltanski e Chiapello (2009) sobre o networker (ou redeiro), o tipo ideal bem sucedido desse sistema, é preciso que, no fim de um projeto, algo lhe seja atribuído e publicamente associado a seu nome. Sem esse último passo, isto é, sem a publicização dos feitos, das realizações e dos atributos que constituem as provas, o exercício não está completo. A apresentação do eu nesses ambientes seria pautada pelo gerenciamento cuidadoso dos símbolos que conferem status, respondendo à demanda de adaptação dos selves ao universo simbólico do capitalismo conexionista. A capacidade de ser bem-sucedido dependeria da exibição correta dos símbolos de sucesso desse universo simbólico e seria o caminho para aumentar a rede de contatos e amigos, um dos maiores sinais de aprovação que o indivíduo pode ter.

Tornou-se frequente os empregadores checarem as informações disponíveis na Internet sobre candidatos a vagas de emprego ou mesmo de candidatos ingressantes em universidades, no caso dos Estados Unidos. É suposto que as informações encontradas online revelem tanto ou mais do que se apreende na entrevista tradicional. A quantidade de amigos no Facebook, por exemplo, pode ser quesito a ser julgado numa seleção profissional. Na pesquisa de Gershon (2011), alguns estudantes relataram que potenciais empregadores checaram seus perfis no Facebook para saber quantos amigos tinham, como medida de seu potencial para constituir redes de contatos. Na tentativa de ajudar os estudantes a evitarem o comprometimento de sua imagem online, consultores especializados passaram a ajudá-los a gerenciar sua identidade digital para apagar rastros comprometedores.

O mesmo ocorre no mundo do trabalho. Além da quantidade de amigos e o número de comentários recebidos em cada postagem, as informações divulgadas nas mídias sociais podem ser decisivas para uma contratação. Uma pesquisa realizada pela empresa CareerBuilder em 2017 descobriu que 70\% dos 2.186 gerentes e profissionais de Recursos Humanos (RH) entrevistados utiliza(va)m redes sociais para verificar potenciais candidatos (SALM, 2017). Isso significa que 2 em cada 5 companhias procuram informações online sobre seus candidatos, a fim de avaliar seu caráter e personalidade. Acerca das razões para o uso das redes sociais com esse propósito, $65 \%$ afirmaram que o fazem para verificar se o candidato se apresenta profissionalmente online, $50 \%$ queriam saber se o perfil do candidato se encaixava na cultura da empresa e outros $45 \%$ queriam conhecer melhor suas qualificações.

\footnotetext{
3 Ver, por exemplo, o artigo de Carla Rodrigues (2010), em que a autora também explora as afinidades entre o capitalismo informacional e a manifestação de suas exigências profissionais nas redes sociais.
} 
A mesma pesquisa mostrou que um terço dos empregadores disse que encontrou em sua busca algo que os fez não contratar algum candidato, como fotos provocativas, informações inapropriadas ou evidência de uso de álcool e outras drogas. Outras razões para a desistência da contratação seriam a demonstração de poucas habilidades comunicativas no perfil, a difamação de antigos empregadores, ou comentários ofensivos relacionados a gênero, etnia ou religião.

Contudo, os empregadores também disseram encontrar informações que incentivaram a contratação, tais como a demonstração de uma personalidade interessante no perfil da rede social e um amplo número de conexões. Houve ainda casos de postagens de boas referências sobre os candidatos feitas por colegas ou a demonstração de qualidades, tais como criatividade, boas conexões e habilidades comunicacionais.

A orientação da empresa que realizou a pesquisa e dos redatores da revista Forbes (SMITH, 2013) é de que os candidatos não deixem de postar informações nas redes sociais por medo da rejeição de potenciais empregadores, mas sim que "trabalhem para criar boas redes e perfis online que representem positivamente suas habilidades e suas experiências profissionais". E acrescentam: "candidatos silenciosos ou invisíveis online estão em desvantagem. Eles precisam engajar-se nas redes sociais para aumentarem sua visibilidade e sua procura para eventuais empregadores".

Helene Cavalli, vice presidente de marketing na Lee Hecht Harrison (SMITH, 2013, n.p.), concorda: "Não é suficiente apenas manter um perfil e checar as atualizações. É preciso ser ativo, produzir conteúdo, participar em discussões de grupo, compartilhar expertise, indicar um artigo para alguém. Você tem de trabalhar em cima de seu perfil. Ainda que se sinta desconfortável fazendo isso, se está à procura de emprego, ser tímido só irá prejudicá-lo".

A coleta de informações pessoais, entretanto, não se limita ao processo seletivo. Muitas empresas têm utilizado tecnologias de medição digital e monitoramento de atividades para descobrir quais características e comportamentos estão envolvidos no desempenho bem-sucedido de tarefas, para identificar com precisão não somente os melhores desempenhos, mas quais características pessoais apresentam. Cada e-mail, mensagem, ligação telefônica e página navegada deixa rastros que podem ser seguidos pelos gestores. O time de cientistas especialistas em comportamento em Knack uma firma do tipo start-up do Vale do Silício, por exemplo, utiliza jogos de computadores e medições constantes, para testar a inteligência emocional, as habilidades cognitivas, a memória de trabalho e a propensão a assumir riscos de seus empregados (LOHR, 2013). Essas informações, obtidas com a ajuda das novas tecnologias, fornecem insights sobre como as pessoas trabalham e se comunicam no ambiente de trabalho, com a justificativa de aumentar a eficiência e a inovação das empresas. 
Assim o número de conexões e participação ativa nas redes sociais tornaramse medidas de avaliação para verificar a demonstração de qualidades prezadas pela ordem simbólica conexionista. Outro dado fundamental que deve ser reiterado é a relação direta entre a popularidade de um perfil (número de seguidores) e a quantidade de informações privadas que o perfil revela. Perfis populares nas mídias sociais, que ficaram conhecidos como influenciadores, ou seja, pessoas que influenciam outras no seu comportamento ou na compra de produtos, em geral são usuários que ativamente exibem seu cotidiano e sua vida pessoal com riqueza de detalhes.

Em 2017, tornou-se popular no Instagram a hashtag \#vanlife, que retrata a vida de jovens casais que deixaram seus empregos nas grandes cidades para viverem em uma van, ou furgão, viajando e tirando fotos das paisagens paradisíacas que atravessam suas aventuras e postando-as no Instagram para milhares de seguidores que acompanham as postagens. A hashtag tinha mais de 1 milhão e meio de publicações públicas no Instagram em meados de 2017, sendo que a maioria procede dos Estados Unidos, da França e da Inglaterra. Com suas fotos retratando o cotidiano da vida na van, esses jovens atraem milhares de seguidores para seus perfis, o que, por sua vez, atrai anunciantes e permite que eles possam extrair renda a partir de seu estilo de vida. Esse é um aspecto fundamental do fenômeno, já que em nenhum outro momento da história é possível identificar esse vínculo direto, sem mediações, entre a intimidade e a esfera econômica. A despeito do argumento, defendido por autores como Zelizer (2002), de que as relações econômicas sempre fizeram parte da esfera íntima, é imprescindível observar que, embora isso seja verdadeiro, a relação entre intimidade e economia foi significativamente transformada ao longo do tempo ${ }^{4}$ na direção de uma proximidade cada vez maior entre uma e outra.

Em abril de 2017, o The New Yorker publicou um artigo contando algumas histórias de pessoas que vivem a \#vanlife (MONROE, 2017). O casal King e Smith, por exemplo, tornou-se uma espécie de celebridade das mídias sociais, com mais de um milhão de seguidores, documentando sua vida invejável. King, 32 anos, trabalhava como executiva, e Smith, 31 anos, era um ciclista profissional e gerente de uma loja de artigos esportivos. Ambos deixaram seus empregos para trás e decidiram viver numa van, viajando pelos Estados Unidos. O casal já postou mais de 1300 fotos em seu perfil. As primeiras fotos ainda continham certo amadorismo e menos curtidas - do que as mais recentes, que revelam como as habilidades de compor e editar as imagens de King melhoraram com o tempo, assim como sua capacidade de perceber o que a audiência quer ver. King afirma ter adquirido uma percepção desconcertante de observar a própria vida tornar-se uma marca. Conforme adquiria mais seguidores e mais anunciantes para seu perfil, diminuía a distância

4 Para mais informações, ver Thibes (2014). 
entre a marca e a vida. Eles são patrocinados por várias empresas cujos produtos divulgam nas fotos, incluindo o TruthPaste, que faz pasta de dentes à base de argila e a Four Sigmatic, uma empresa de super foods que vende café instantâneo com elixires de cogumelos (MONROE, 2017).

A busca por celebridades para fazer propaganda não é nova, mas agora o marketing de influência expande a categoria de celebridade para incluir blogueiras, it-girls, adolescentes que contam piadas e cachorros fotogênicos. Segundo o artigo (MONROE, 2017), os anunciantes não procuram pessoas como King e Smith porque eles são celebridades no sentido tradicional, mas porque eles possuem um vínculo emocional com seus seguidores. Esse vínculo é criado a partir da sensação que os seguidores adquirem de intimidade em relação ao perfil, uma vez que acompanham o cotidiano e a vida pessoal retratados pelas fotos e vídeos. O vínculo criado entre os seguidores e os influenciadores é, desse modo, aproveitado pelas marcas. Um estudo estimou que o mercado de mídia social-influente valia 500 milhões de dólares em 2015; espera-se que esse mercado aumente para pelo menos cinco bilhões de dólares até 2020 .

Os principais influenciadores das mídias sociais recebem dezenas de milhares de dólares por endossar um produto. No Brasil, a \#vanlife ainda não é tão popular como nos Estados Unidos, mas o fenômeno dos influenciadores das mídias sociais é tão importante aqui quanto lá e no resto do mundo. Camila Coelho (2017), por exemplo, é uma blogueira e maquiadora brasileira que se tornou conhecida em 2010 com um canal no YouTube apresentando vídeos tutoriais sobre maquiagem. Seus vídeos não apenas ensinam as pessoas a se maquiar, mas mostram sua vida pessoal, suas viagens pelo exterior, seu cotidiano e os produtos que ela consome. Seu perfil do Instagram é povoado por imagens de sua vida íntima, tais como uma foto dela tomando café da manhã de roupão em um hotel em Paris, por exemplo. Atualmente, ela possui milhões de seguidores no Youtube e no Instagram, o que a torna uma grande influenciadora no mercado do marketing online.

A retratação da intimidade por meio de fotografias não é um fenômeno novo. O costume de capturar cenas íntimas em retratos data de meados do século XIX, quase junto ao surgimento da própria câmera fotográfica, num século que prezava como nenhum outro o âmbito íntimo e a separação entre as esferas pública considerada perigosa e mundana - e o privado, vinculado, por sua vez, à santidade do lar, da família e da própria subjetividade do sujeito. As fotos íntimas tinham como propósito "manter viva a memória familiar, algo primordial para as subjetividades típicas dessa época", criando uma conexão com o passado e um "mergulho na própria interioridade" (SIBILIA, 2011, p.131). Uma boa foto deveria registrar a verdadeira personalidade do fotografado, captando aquilo que emanava do interior de sua pessoa e de certa maneira se expressava em seu aspecto visível, por isso, 
não faria sentido serem amplamente exibidas (SIBILIA, 2011). Citando o exemplo de Roland Barthes, Sibilia (2011) recorda que, no ensaio intitulado $A$ câmara clara (1984), o autor se propôs a definir o que era a fotografia em si, no entanto, mesmo depois de analisar uma diversidade de imagens históricas, publicitárias e artísticas, sentia-se pesaroso por não ter conseguido atingir a meta. Foi quando decidiu prestar atenção a outro tipo de fotografia, observando as fotos de sua mãe recentemente falecida. Num único retrato de sua mãe, quando ela ainda era uma menina de cinco anos de idade, Barthes afirmou ter encontrado "a verdade" sobre o que havia sido aquela mulher - posto que "essa fotografia reunia todos os predicados possíveis do que constituía o ser de minha mãe" (BARTHES, 1984, p.106, apud SIBILIA, 2011, p.132), assim como a essência da própria fotografia em si. Porém, a despeito disso, Barthes tomou a decisão de não mostrar a foto de sua mãe no livro, já que seu significado não poderia ser compartilhado. Como observa Sibilia (2011), do mesmo modo que certas fotografias impressas em papel ou álbuns antigos, essa imagem era tão íntima e reveladora da personalidade da mãe de Barthes, que devia ser preservada e mantida a salvo dos olhos intrusos.

Confrontando os exemplos mobilizados das imagens publicadas nas redes sociais e aquelas registradas no álbum de fotos antigo, fica claro como o sentido dado ao registro da intimidade mudou. Se antes havia o propósito de se conectar com o passado e com a própria interioridade, ou ainda com aqueles com quem se tinha uma relação próxima, fortalecendo esses vínculos, hoje há um imperativo quantitativo em jogo: a ampliação de conexões fracas, com observadores da intimidade anônimos.

Como observa Simmel (2002), algumas relações só podem ser manter por seu caráter íntimo. A intimidade aparece como um tipo de relação que ocorre no que ele denomina de formação sociológica mais simples, isto é, a díade, ou mais simplesmente, a relação que ocorre entre duas partes. O que há de específico nessa relação é que cada uma das partes se sente confrontada apenas pelo outro e não pela coletividade que há acima deles. A díade é sujeita a tonalidades que a tornam especial ou trivial; especial quando as partes sentem que o que existe em sua relação é único, ou raro, e trivial quando o conteúdo pode ser usualmente repetido. A trivialidade nas relações entre duas partes aparece, pois, como uma característica negativa, uma ameaça. $\mathrm{O}$ fato de que a díade não se torne uma estrutura maior, que ultrapassa os dois elementos, é a base da intimidade, de acordo com Simmel (2002). O que por sua vez conforma o caráter íntimo de algumas relações está estritamente ligado à crença do indivíduo que o que ali transcorre não é partilhado por mais ninguém além das duas partes.

Assim, a condição para a existência da intimidade é a própria exclusividade do que ocorre em uma relação. Portanto, quando passamos a compartilhar cenas de 
nossa intimidade com uma pluralidade de seguidores, o registro certamente perderá seu caráter íntimo. Dando consequências a essa constatação, podemos afirmar que, quando a vida pessoal, a personalidade e a própria intimidade relacionam-se à esfera pública e econômica de modo nunca antes tão próximo, os sentidos conferidos ao privado e sua própria essência são transformados, tornando sua vivência cada vez mais restrita na contemporaneidade.

\section{MARKET OF INTIMACY: THE RELATIONSHIP BETWEEN PERSONAL LIFE AND THE ECONOMIC SPHERE}

ABSTRACT: The Online self disclosure has become ubiquitous and regular in the daily lives of people with Internet access. In this article we review some theories that intend to explain this phenomenon. After that, we propose an explanatory hypothesis based on the transformations regarding the contemporary relation between the economic system and the personal life.

KEYWORDS: Intimacy. Economy. Privacy. Internet.

\section{REFERÊNCIAS}

ACQUISTI, A., STUTZMAN, F., GROSS, R. Silent Listeners: The Evolution of Privacy and Disclosure on Facebook. Journal of Privacy and Confidentiality, Number 2, 7 - 41, 2012.

ACQUISTI, Alessandro e GROSS, Ralph. Imagined communities: awareness, information sharing and privacy on Facebook. Paper presented at the Privacy Enhancing Technology Workshop. Cambridge, 2006.

BARTHES, R. A Câmara Clara. Rio de Janeiro: Nova Fronteira, 1984.

BENJAMIN, W. Charles Baudelaire: Um Lírico no Auge do Capitalismo. Obras Escolhidas III. Ed. Brasiliense, $1^{\mathrm{a}}$.edição, 1989, p.33-65.

BOltansKi, Luc, CHIAPELlo, Ève. O Novo Espírito do Capitalismo. Trad. Ivone C. Beneditti. São Paulo: Martins Fontes, 2009.

BRASIL. Presidência da República. Secretaria de Comunicação Social. Pesquisa brasileira de mídia 2015: hábitos de consumo de mídia pela população brasileira. Brasília: Secom, 2014. Disponível em: ww.secom.gov.br/.../pesquisa/...pesquisas.../pesquisa-brasileira-demidia-pbm-2015. Acessado em: 2 dez. 2017. 
COELHO, Camila. Blog. Disponível em: https://www.youtube.com/channel/UCnmaW_ YVh9iJAFVOsLR7W2w. Acessado em: 2 dez. 2017.

DEAN, Jodi. Democracy and Other Neoliberal Fantasies: Communicative Capitalism and Left Politics. Durham: Duke University Press, 2009.

EHRENBERG, Alain. O Culto da Performance: da aventura empreendedora à depressão nervosa. Trad. Pedro F. Bendassolli. Aparecida: Idéias e Letras, 2010.

. L’individu Incertain. Calmann-Lévy, 1995.

ELLISON, Nicole B., VITAK, Jessica, STEINFIELD, Charles, GRAY, Rebecca and LAMPE, Cliff. Negotiating Privacy Concerns and Social Capital Needs in a Social Media Environment. In: TREPTE, S. AND REINECKE, L. (Eds.). Privacy Online: Perspectives on Privacy and Self-Disclosure in the Social Web. Berlin, Heidelberg, Germany: SpringerVerlag, 2011.

ELLISON, N. B. \& boyd, d. Sociality through Social Network Sites. In Dutton, W. H. (Ed.). The Oxford Handbook of Internet Studies. Oxford: Oxford University Press, p. 151-172, 2013.

GERSHON, Ilana. Un-friend my heart: Facebook, Promiscuity, and a Hesrtbreak in a Neoliberal Age. Anthropological Quarterly, vol. 84, No. 4, p.865-894, 2011.

GOFFMAN, Erving. Interaction ritual: essays in face-to-face behavior. New Brunswick, N.J.: Aldine Transaction, 2005.

KEMP, Simon. DIGITAL IN 2016. We Are Social. 27 january 2016. Disponível em: https:// wearesocial.com/uk/special-reports/digital-in-2016. Acessado em: 2 dez. 2017.

LASCH, Christopher. The Culture of Narcissism: american life in an age of diminishing expectations, New York - London: W. W. Norton \& Company, 1979.

LOHR, Steve. Big Data, Trying to Build Better Workers. The New York Times. APRIL 20, 2013.

MADDEN, MARYeT et al. Teens, Social Media, and Privacy. Washington, DC: Pew Research Center, Internet and American Life Project, 2013. Disponível em: pewinternet. org/Reports/2013/Teens-Social-Media-And-Privacy/Summary-of-Findings.aspx. Acessado em: 11 dez. 2017.

MONROE, Rachel. \#Vanlife, the Bohemian Social-Media Movement: What began as an attempt at a simpler life quickly became a life-style brand. The New Yorker. American Chronicles, April 24, 2017 Issue. Disponível em: https://www.newyorker.com/ magazine/2017/04/24/vanlife-the-bohemian-social-media-movement. Acessado em: $2 \mathrm{dez}$. 2017. 
PAPACHARISSI, Zizi. The virtual geographies of social networks: a comparative analysis of Facebook, LinkedIn and ASmallWorld. New Media \& Society. Vol 11, Issue 1-2, pp. 199 - 220. First Published February 1, 2009.

PRICKETT, Sarah Nicole. Look Out, It's Instagram Envy. The New York Times. Style Magazine. NOV. 6, 2013.

RODRIGUES, Carla. Capitalismo informacional, redes sociais e dispositivos móveis: hipóteses de articulação. Revista Galáxia, São Paulo, n. 20, p. 70-83, dez. 2010.

SALM, Lauren. 70\% of employers are snooping candidates' social media profiles. CareerBuilder Survey. June 15, 2017. Disponível em: https://www.careerbuilder.com/ advice/social-media-survey-2017. Acessado em: 11 dez. 2017.

SENNET, Richard. The Fall of Public Man. New York - London: W. W. Norton \& Company, 1977.

SIBILIA, Paula. Vitrines da intimidade na internet: Imagens para guardar ou para mostrar? Revista Estudos de Sociologia. UNESP, Araraquara, v.16, n.30, p.127-139, 2011.

. O show do eu: a intimidade como espetáculo. Rio de Janeiro: Nova Fronteira, 2008.

SIMMEL, Georg. The Sociology of Secrecy and of Secret Societies. American Journal of Sociology, Volume 11, Issue 4 Jan. p. 441-498, [1906] 2002.

SMITH, Jacquelyn. "How Social Media Can Help (Or Hurt) You In Your Job Search". Revista Forbes. 16 de abril de 2013, n.p. Disponível em: https://www.forbes.com/ sites/jacquelynsmith/2013/04/16/how-social-media-can-help-or-hurt-your-job-search/ \#6d807f857ae2. Acessado em: 11 dez. 2017.

STUTZMAN, Frederic. An Evaluation of Identity-Sharing Behavior in Social Network Communities. Journal of the International Digital Media and Arts Association. 3 (1), p.10-18, 2006. Disponível em: citeseerx.ist.psu.edu/viewdoc/download?doi=10.1.1.91. Acessado em: 2 dez. 2017.

THIBES, Mariana Z. A vida privada na mira do sistema: a Internet e a obsolescência da privacidade no capitalismo conexionista. 2014. 222 f. Tese (Doutorado em Sociologia). Faculdade de Filosofia, Letras e Ciências Humanas da Universidade de São Paulo, São Paulo, 2014.

TREPTE, S.; REINECKE, L. (Eds.). Privacy Online: Perspectives on Privacy and SelfDisclosure in the Social Web. Berlin, Heidelberg, Germany: Springer-Verlag, 2011. 
WELLMAN, B., \& GULIA, M. Virtual communities as communities: Net surfers don't ride alone. In Smith, M.A., \& Kollock, P. (Eds.), Communities in Cyberspace. (p. 167-194). New York: Routledge, 1999.

ZELIZER, Viviana A. The Purchase of Intimacy. Princeton University Press, 2005.

Recebido em: 14/08/2017.

Aprovado em: 23/11/2017. 
